\title{
Registros de perdiz Rhynchotus rufescens (Aves, Tinamiformes, Tinamidae) no interior da Reserva Natural Vale, Linhares, Espírito Santo, sudeste do Brasil
}

\author{
Ana Carolina Srbek-Araujo ${ }^{1,2}$ \& Adriano Garcia Chiarello Ch, $^{2,3}$ \\ ${ }^{1}$ Instituto Ambiental Vale, \\ Rodovia BR-101, Km 122, s/n, Bairro Interior, CEP 29900-970, Linhares, ES, Brasil, \\ e-mail:srbekaraujo@hotmail.com \\ ${ }_{2}^{2}$ Programa de Pós-Graduação em Zoologia de Vertebrados, \\ Pontifícia Universidade Católica de Minas Gerais - PUC Minas, \\ Av. Dom José Gaspar, 500, Bairro Coração Eucarístico, CEP 30535-610, Belo Horizonte, MG, Brasil \\ ${ }^{3}$ Autor para correspondência: Adriano Garcia Chiarello,e-mail: bradypus@pucminas.com.br
}

SRBEK-ARAUJO, A.C. \& CHIARELLO, A.G. 2008. Observations of the tinamou Rhynchotus rufescens (Aves, Tinamiformes, Tinamidae) inside Reserva Natural Vale, Linhares, Espírito Santo, southeastern Brazil. Biota Neotrop. 8(2): http://www.biotaneotropica.org.br/v8n2/en/abstract?short-communication+bn01808022008.

\begin{abstract}
The present communication reports records of the tinamou (Rhynchotus rufescens) made in the interior of the forested area of Reserva Natural Vale (RNV). This reserve has a large area (21,787 ha) and is covered predominantly by primary forests. Six tinamou sightings were obtained between 2005 and 2007 in places located within the forest from 70 to 5,500 $\mathrm{m}$ of distance to the nearest forest edge, indicating that this Cerrado-dwelling tinamou is using the forested interior of the reserve. Previous observations and reports from other authors had already confirmed the presence of this bird in open areas adjacent to the RNV and Sooretama Biological Reserve, which is contiguous to the former, however this is the first time this tinamou is observed within the forest. The potential impacts the entrance of this bird represents to other tinamou species, like contamination with parasites and pathogens and the introduction of exotic grass species, are briefly discussed.
\end{abstract}

Keywords: Atlantic forest, fragmentation, exotic species.

SRBEK-ARAUJO, A.C. \& CHIARELLO, A.G. 2008. Registros de perdiz Rhynchotus rufescens (Aves, Tinamiformes, Tinamidae) no interior da Reserva Natural Vale, Linhares, Espírito Santo, sudeste do Brasil. Biota Neotrop. 8(2): http://www.biotaneotropica.org.br/v8n2/pt/abstract?shortcommunication+bn01808022008.

Resumo: A presente comunicação reporta observações de perdiz (Rhynchotus rufescens) efetuadas no interior da área florestada da Reserva Natural da Vale (RNV). A Reserva apresenta grande extensão ( 21.787 ha) e é coberta predominantemente por florestas primárias. Seis registros foram obtidos no período de 2005 a 2007, em locais distantes entre 70 e $5.500 \mathrm{~m}$ da borda florestal mais próxima, indicando que esta espécie de Cerrado está utilizando partes internas e florestadas da Reserva. Observações anteriores e relatos de outros autores já haviam confirmado a presença da perdiz em áreas abertas adjacentes à RNV e à Reserva Biológica de Sooretama, que é contígua à anterior, mas esta é a primeira vez em que a presença desta ave campestre é relatada para o interior da floresta. Os impactos potenciais que a entrada da perdiz representa para as espécies nativas e florestais de tinamídeos, como a contaminação por parasitas e patógenos e a introdução de capim exótico, são brevemente discutidos.

Palavras-chave: espécie exótica, fragmentação, Mata Atlântica. 


\section{Introdução}

A perdiz (Rhynchotus rufescens Temminck, 1815) ocorre naturalmente em regiões campestres, cerrados e buritizais, podendo estar presente também em planaltos descampados, estando associada a habitats úmidos (Sick 1997). A espécie tem sido favorecida pela expansão das áreas de pastagem no país, tendo alcançado o estado do Espírito Santo por volta de 1968 (Sick 1997). A perdiz está atualmente associada a áreas de pasto sujo do norte do Espírito Santo e sul da Bahia (Sick 1997), tendo invadido também pastagens da região serrana do primeiro estado (município de Santa Teresa; Willis \& Oniki 2002).

O Espírito Santo apresenta-se em sua totalidade inserido no bioma Mata Atlântica, possuindo aproximadamente $87 \%$ de sua área originalmente coberta por florestas nativas (Fundação SOS Mata Atlântica \& INPE 2002). Atualmente, sua área florestal total encontra-se reduzida a cerca de $11,24 \%$ da extensão original (Fundação SOS Mata Atlântica \& INPE 2005).

A presente comunicação reporta a ocorrência de perdiz em áreas florestadas localizadas no interior da Reserva Natural Vale (RNV), apresentando a reunião de registros ocasionais efetuados entre 2005 e 2007.

\section{Material e Métodos}

A RNV localiza-se $30 \mathrm{~km}$ ao norte do Rio Doce, entre os municípios de Linhares e Jaguaré (19 $06^{\circ}-19^{\circ} 18^{\prime} \mathrm{S}$ and $39^{\circ} 45^{\prime}-40^{\circ} 19^{\prime} \mathrm{W}$ ), norte do Espírito Santo. A Reserva está inserida em uma das áreas de extrema importância biológica para a conservação da biodiversidade da Mata Atlântica, estando localizada no Corredor Central da Mata Atlântica (Ministério do Meio Ambiente 2000). Com aproximadamente 21.787 ha de extensão, a RNV representa parcela significativa da área de Mata Atlântica Primária remanescente do Espírito Santo e constitui a segunda maior reserva de Mata dos Tabuleiros ou Zona Tabular Costeira (Hiléia Baiana) do estado. Associada à Reserva Biológica de Sooretama (24.250 ha), constitui um bloco praticamente contínuo de mata que representa cerca de $9,46 \%$ da área florestal de cobertura original de Mata Atlântica remanescente no estado, incluindo áreas primárias e remanescentes em regeneração (Fundação SOS Mata Atlântica \& INPE 2005), e a maior área de preservação ao norte do Rio de Janeiro. A Reserva apresenta relevo relativamente plano, com uma sequiência de colinas tabulares, apresentando altitudes entre 28 e 65 m (Jesus \& Rolim 2005). De acordo com a classificação de Köppen, o clima na região é do tipo tropical quente e úmido (Awi), apresentando estação chuvosa no verão e seca no inverno (Jesus \&
Rolim 2005). A temperatura média anual é de $23,3^{\circ} \mathrm{C}$, variando entre 14,8 e $34,2{ }^{\circ} \mathrm{C}$ (média das mínimas e máximas, respectivamente), com uma precipitação pluviométrica média anual de $1.202 \mathrm{~mm}$, caracterizada por uma forte variabilidade entre anos (Jesus \& Rolim 2005). A RNV está localizada nos domínios da Floresta Ombrófila Densa, segundo o Mapa de Vegetação do Brasil (IBGE 1993), sendo classificada como Floresta Estacional Perenifólia por Jesus \& Rolim (2005), que representa uma tipologia intermediária entre a primeira e a Floresta Estacional Semidecídua. A rede de drenagens local revela-se dendrítica/dicotômica, sendo formada por um conjunto de córregos tributários do Rio Barra Seca (Jesus \& Rolim 2005). A RNV foi formada a partir da compra de diversas propriedades (processo iniciado na década de 50), apresentando um contorno não regular (recortado) e possuindo uma rede de estradas internas inicialmente abertas para retirada de madeira que seria destinada à produção de dormentes para abastecimento da Estrada de Ferro Vitória-Minas. Felizmente, resultados iniciais do manejo de uma pequena área (década de 60) revelaram que este projeto não seria viável economicamente e a floresta foi mantida como reserva pela Vale desde então (Jesus \& Rolim 2005). Atualmente, o entorno da Reserva está constituído principalmente por pastagens, sendo também encontradas áreas destinadas ao cultivo de mamão, café e eucalipto, entre outras culturas (Chiarello 1999, Jesus \& Rolim 2005).

Os registros de perdiz efetuados na área interna da RNV foram obtidos ocasionalmente, durante a execução de atividades relacionadas a projetos de pesquisa em desenvolvimento no interior da Reserva (transecções lineares ou deslocamentos entre áreas com o auxílio de veículos). Para cada registro obtido foi observado o horário de obtenção do mesmo, a menor distância do espécime em relação à borda da Reserva em contato com áreas abertas alteradas (pastagens ou culturas diversas) e a caracterização da borda/área adjacente.

\section{Resultados e Discussão}

Ao todo foram obtidos seis avistamentos de perdiz no interior da RNV, em diferentes distâncias da borda, tendo sido efetuados sempre na estação chuvosa, em áreas de Floresta Estacional Perenifólia (Tabela 1). O primeiro registro foi obtido durante atividades de transecção linear em trilha localizada no interior da mata, próximo à borda da Reserva, e os outros cinco registros foram efetuados durante deslocamento em estradas de terra ( $\sim 4 \mathrm{~m}$ de largura) localizadas no interior da RNV.

Para o penúltimo registro obtido (20 de novembro de 2006), ressalta-se que o ponto de avistamento da perdiz estava localizado a

Tabela 1. Registros de perdiz (Rhynchotus rufescens) efetuados no interior da Reserva Natural da Vale, no período de 2005 a 2007.

Table 1. Records of the tinamou (Rhynchotus rufescens) inside the Reserva Natural Vale from 2005 to 2007.

\begin{tabular}{|c|c|c|c|}
\hline Data & Horário & DBP $(\mathbf{m}) *$ & Local \\
\hline 17 de março de 2005 & $14: 08$ & 200 & $\begin{array}{l}\text { Transecto localizado próximo à borda da Reserva em contato com área de } \\
\text { pastagem. }\end{array}$ \\
\hline 14 de dezembro de 2005 & $17: 33$ & 70 & $\begin{array}{l}\text { Estrada do Flamento, próximo à borda em contato com área utilizada no cultivo } \\
\text { de mamão. }\end{array}$ \\
\hline 25 de janeiro de 2006 & $16: 21$ & 1.000 & $\begin{array}{l}\text { Estrada do Guaribu Amarelo, cujo aceiro mais próximo encontra-se em contato } \\
\text { com área de pastagem. }\end{array}$ \\
\hline 20 de novembro de 2006 & $14: 59$ & 5.500 & $\begin{array}{l}\text { Estrada da Gávea, distante de áreas externas alteradas (compostas por culturas } \\
\text { diversas). }\end{array}$ \\
\hline 26 de fevereiro de 2007 & $17: 18$ & 700 & $\begin{array}{l}\text { Estrada da Gávea, cuja borda mais próxima está constituída por área utilizada } \\
\text { no cultivo de cana-de-açúcar. }\end{array}$ \\
\hline
\end{tabular}

*Distância do registro com relação à borda mais próxima. 
cerca de 2.400 metros de uma área de "nativo" (denominação local), constituído por vegetação naturalmente aberta e esparsa em área com solo arenoso (estrutura vegetacional original). Esta área está circundada parcialmente por vegetação florestal, estando isolada de áreas externas à RNV por meio de um extenso corpo d'água (barreira física que delimita a Reserva em sua porção norte e nordeste).

De forma geral, observa-se que em todos os registros, particularmente naqueles obtidos durante deslocamentos em estradas internas (melhor luminosidade e maior visibilidade), foi possível a observação de detalhes morfológicos e de características da plumagem dos espécimes, permitindo a identificação inequívoca da espécie. De acordo com relatos de funcionários antigos da Reserva, a espécie não era encontrada no interior da RNV até meados da década de 1980, quando passou a ser observada esporadicamente nas estradas internas, a partir de registros que têm se tornado lenta e gradativamente mais frequientes, embora ainda possam ser considerados raros.

Para o registro efetuado em 14 de dezembro de 2005, ressalta-se que a ave se encontrava a uma pequena distância da borda, próximo ao contato da Reserva com áreas abertas alteradas. Neste sentido, é provável que o espécime registrado estivesse utilizando áreas de mata estruturalmente alteradas pelos efeitos de borda (estrada próxima ao aceiro da Reserva), que se revelam em geral mais acentuados nos primeiros 50-80 m da borda (Murcia 1995, Laurance et al. 2002, A.G. Chiarello, dados não publicados). De forma semelhante, no registro do dia 17 de março de 2005, embora a perdiz tenha sido detectada no interior da mata, o local estava muito próximo de área de pasto adjacente, tendo sido avistada a partir de um transecto linear disposto paralelamente à borda da Reserva. Entretanto, para os outros quatro avistamentos ( 25 de janeiro, 21 de outubro e 20 de novembro de 2006 e 26 de fevereiro de 2007), embora a ave tenha sido observada no leito de estradas internas, ressalta-se que os registros foram realizados a distâncias significativas em relação à borda alterada mais próxima. Neste sentido, considera-se que a existência de estradas possa favorecer a entrada e o deslocamento da perdiz no interior da Reserva, embora os dados obtidos não permitam afirmar que sua presença esteja restrita aos acessos ou às porções de mata mais próximas à borda, indicando o uso efetivo de áreas internas à Reserva pela espécie. Desta forma, a perdiz estaria atualmente associada a ambientes localizados no interior de áreas florestadas, não restringindo sua invasão às áreas de pastagem presentes no estado ou a trechos localizados próximo à borda da Reserva (distância média dos registros obtidos $=1.512 \mathrm{~m}$ ). Sob estes aspectos, considera-se que a presença de perdiz em áreas florestadas possa ser considerada um efeito de borda, cuja extensão na RNV tem alcançado áreas internas distantes da borda florestal. Em estudo realizado em 1998, Marsden et al. (2001) citam a presença de perdiz na RNV, mas o único registro foi efetuado na borda da Reserva (M. Galetti, comunicação pessoal). De maneira semelhante, durante pesquisas anteriormente conduzidas na RNV e na Reserva Biológica de Sooretama (Chiarello 1999), a perdiz foi detectada através do canto, com relativa frequiência, em áreas de pastagem adjacentes às reservas amostradas (A.G. Chiarello, observação pessoal), o que coincide com informações recentes fornecidas por moradores locais.

A presença da perdiz em áreas florestadas pode trazer riscos às espécies nativas de tinamídeos de médio e grande porte que apresentam hábito tipicamente florestal, como o macuco (Tinamus solitarius), o jaó (Crypturellus noctivagus noctivagus) e o chororão (Crypturellus variegatus), por exemplo, estando estas espécies, entre outras, presentes na RNV (A.G. Chiarello, observação pessoal). Embora seja possível algum nível de competição entre a perdiz e tinamídeos florestais (estudos futuros poderão testar esta hipótese), a possibilidade de intercâmbio de parasitas e patógenos, tanto da espécie invasora para as nativas, quanto no sentido contrário, pode representar maior potencial de impacto. Segundo Mapeli et al. (2003), os tinamídeos estão naturalmente expostos a infecções por helmintos como consequiência da utilização de pequenos artrópodes e moluscos como recurso alimentar, destacando-se principalmente as infecções causadas por parasitos cuja evolução utiliza estes grupos como hospedeiros intermediários. A ação patogênica das helmintoses é ainda pouco conhecida, embora sejam reconhecidos relatos de mortalidade de espécimes como consequiência da ação patogênica própria do helminto, pela associação a infecções bacterianas secundárias e pela depreciação do crescimento dos animais (Freitas \& Almeida 1935). Mapeli et al. (2003) relatam ainda a presença de helmintos (duas espécies de nematódeos e um trematódeo) em perdizes criadas em cativeiro (Setor de Animais Silvestres da Faculdade de Ciências Agrárias e Veterinárias - UNESP, município de Jaboticabal / São Paulo), cujo plantel foi estabelecido originalmente por espécimes provenientes do Rio Grande do Sul. De forma semelhante, $41 \%$ dos tinamídeos analisados por Freitas et al. (2002) apresentaram parasitas gastrointestinais, considerando aves silvestres mantidas no Criatório Científico e Cultural Chaparral e no Parque Dois Irmãos (município de Recife, Pernambuco). Além de helmintos, é reconhecida a presença de outros parasitas em tinamídeos, tendo sido identificados, por exemplo, cinco espécies de piolhos malófagos (Ordem Mallophaga, Sub-Ordem Ischnocera, Família Heptapsogastridae) em um único Inhambu-guaçu (Crypturellus obsoletus) proveniente do município de Petrópolis, Rio de Janeiro (Valim et al. 2005). Segundo Ward (1957), os Heptapsogastridae estariam confinados aos tinamídeos sul-americanos, com exceção de duas espécies encontradas em Cariamidae (Ordem Gruiformes). Não há dados ou registros que indiquem uma redução atual das populações de tinamídeos nativos na RNV, sendo, portanto, necessária a realização de estudos específicos para amostragens sistemáticas destes táxons.

Outro possível impacto da entrada da perdiz no interior da Reserva decorre do fato dela poder carrear sementes de espécies exóticas presas à plumagem ou tarsos para o interior de áreas naturais. Destaca-se, por exemplo, a possibilidade de introdução de plantas típicas de áreas abertas, espécies cultivadas regionalmente ou gramíneas, particularmente braquiária (Brachiaria spp.), sendo estas muito abundantes no entorno da RNV. Considera-se que a possibilidade de transporte de sementes destas espécies, associada à presença de clareiras naturais (decorrentes da dinâmica florestal) e áreas com estrutura vegetacional naturalmente aberta na porção interna da Reserva (mussununga e nativo, por exemplo), constitua um cenário favorável à introdução e estabelecimento de gramíneas exóticas.

Embora os dados aqui reunidos sejam limitados, julga-se necessária a realização de estudos mais detalhados que possam avaliar de maneira mais completa e acurada a abundância e distribuição da perdiz no interior da RNV, investigando-se também o real impacto desta ave sobre a flora e fauna locais.

\section{Agradecimentos}

A presente comunicação foi realizada com base em registros obtidos durante coleta de dados dos projetos intitulados "Predação de ovos e abundância relativa do lagarto Teiú (Tupinambis merianae; Lacertília; Teiidae) nas bordas e no interior da Reserva Natural da Vale do Rio Doce - Linhares, Espírito Santo" e "Tamanho Populacional, Densidade e Uso do Hábitat da Onça-pintada (Panthera onca; Carnivora; Felidae) na Reserva Natural Vale do Rio Doce, Linhares, Espírito Santo". Agradecemos à Vale/Instituto Ambiental Vale, especialmente a Renato Moraes de Jesus, pelo apoio logístico durante atividades de campo e financiamento concedido. Ao CNPq pela bolsa produtividade em pesquisa concedida a AGC. 


\section{Referências Bibliográficas}

CHIARELLO, A.G. 1999. Effects of fragmentation of the Atlantic forest on mammal communities in south-eastern Brazil. Biological Conservation 89(1): 71-82.

FREITAS, J.F.T. \& ALMEIDA, J.L. 1935. O gênero “Capillaria” Zeder, 1800 ("Nematoda-Trichuroidea") e as capillarioses nas aves domesticas. Revista do Departamento Nacional de Produção Animal 2(4-6): 310-363.

FREITAS, M.F.L., OLIVEIRA, J.B., CAVALCANTI, M.D.B., LEITE, A.S., MAGALHÃES, V.S., OLIVEIRA, R.A. \& SOBRINHO, A.E. 2002. Parásitos gastrointestinales de aves silvestres en cautiverio en el estado de Pernambuco, Brasil. Parasitología Latinoamericana 57(1-2): 50-54.

FUNDAÇÃO SOS MATA ATLÂNTICA \& INPE. 2002. Atlas dos Remanescentes Florestais da Mata Atlântica / Período 1995-2000. Relatório Final, Fundação SOS Mata Atlântica \& Instituto Nacional de Pesquisas Espaciais, São Paulo.

FUNDAÇÃO SOS MATA ATLÂNTICA \& INPE. 2005. Atlas dos Remanescentes Florestais da Mata Atlântica / Período 2000-2005. Resultados Quantitativos - Estado do Espírito Santo. Relatório Final, Fundação SOS Mata Atlântica \& Instituto Nacional de Pesquisas Espaciais, São Paulo. 4p.

IBGE. 1993. Mapa de Vegetação do Brasil. Fundação Instituto Brasileiro de Geografia e Estatística, Rio de Janeiro.

JESUS, R.M. \& ROLIM, S.G. 2005. Fitossociologia da Mata Atlântica de Tabuleiro. Boletim Técnico da Sociedade de Investigações Florestais 19: 1-149.

LAURANCE, W.F., LOVEJOY, T.E., VASCONCELOS, H.L., BRUNA, E.M., DIDHAM, R.K., STOUFFER, P.C., GASCON, C., BIERREGAARD, R.O., LAURANCE, S.G. \& SAMPAIO, E. 2002. Ecossystem decay of Amazonian Forest fragments: a 22-year investigation. Conservation Biology 16(3): 605-618.

MAPELI, E.B., NASCIMENTO, A.A., SZABÓ, M.P.J. \& TEBALDI, J.H. 2003. Infecções Naturais por Helmintos em Perdizes (Rhynchotus Rufescens Temminck, 1815) de Cativeiro, no Município de Jaboticabal, Estado de São Paulo. Arquivos do Instituto de Biologia 70(4): 415-418.

MARSDEN, S.J., WHIFFIN, M. \& GALETTI, M. 2001. Bird diversity and abundance in forest fragments and Eucalyptus plantations around an Atlantic forest reserve, Brazil. Biodiversity and Conservation 10: 737-751.

MINISTÉRIO DO MEIO AMBIENTE. 2000. Avaliação e Ações Prioritárias para a Conservação da Biodiversidade da Mata Atlântica e Campos Sulinos. MMA/SBF, Brasília.

MURCIA, C. 1995. Edge effects in fragmented forests: implications for conservation. Trends in Ecology and Evolution 10: 58-62.

SICK, H. 1997. Ornitologia Brasileira. $3^{\text {ed }}$. Nova Fronteira, Rio de Janeiro.

VALIM, M.P., BECKER, C.M. \& SERRA-FREIRE, N.M. 2005. Tinamous lice found on a new host [Crypturellus obsoletus (Temminck, 1815)] in Petrópolis, Rio de Janeiro, Brazil. Entomología y Vectores 12(1): 133-136.

WARD, R.A. 1957. A study of the host distribution and some relationships of Mallophaga parasitic on birds of the order Tinamiformes, Part 1. AnnalsEntomological Society of America 50: 335-353.

WILLIS, E.O. \& ONIKI, Y. 2002. Birds of Santa Teresa, Espírito Santo, Brazil: do humans add or subtract species? Papéis Avulsos de Zoologia 42(9): 193-264.

Recebido em 25/10/07 Versão reformulada recebida em 12/03/08 Publicado em 16/05/08 